Physical activity and sport in young transgender adults

\title{
Barriers and facilitators of physical activity and sport participation among young transgender adults who are medically transitioning
}

\begin{abstract}
Background: Transgender people (those who feel incongruence between the gender they were assigned at birth and their gender identity) engage in lower levels of physical activity compared to cisgender people (non-transgender). Several factors have been shown to affect physical activity engagement in the cisgender population however; the physical activity experiences of young transgender adults have not been explored. It was therefore the aim of the current study to understand what factors are associated with physical activity and sport engagement in young transgender adults who are medically transitioning.
\end{abstract}

Method: Semi-structured interviews were conducted with 14 young transgender adults (18-36 years) who had initiated their medical transition at a transgender health service in the United Kingdom. The data were analysed using thematic analysis.

Results: Two main themes were identified: (1) barriers and (2) facilitators to physical activity and sport. Overall, the young transgender adults were insufficiently active due to inadequate changing facilities, body dissatisfaction, fears surrounding 'passing' and not being accepted by others. At the same time, participants were motivated to engage in physical activity to increase their body satisfaction and gender congruence. However, participants felt there were a lack of safe and comfortable spaces to engage in physical activity and sport.

Conclusion: Young transgender adults who are medically transitioning experience several barriers to physical activity and sport, despite being motivated to be physically active. Initiatives to facilitate young transgender adults to be able to put their motivations into practice (i.e. to be more physically active) are needed. 
Physical activity and sport in young transgender adults

Keywords: Physical activity, sport, young transgender adults, medical transition, inclusion 
Physical activity and sport in young transgender adults

\section{Barriers and facilitators of physical activity and sport participation among young transgender adults who are medically transitioning}

\section{Introduction}

Physical activity can be defined as any activity engaged in (e.g., while working, playing, carrying out household chores, travelling, and recreational pursuits) that involves muscularskeletal movement and energy expenditure and is vital for promoting physical and mental wellbeing (Lee et al., 2012; World Health Organisation [WHO], 2016). Across the world in 2010, $23 \%$ of adults (aged 18+) were not active enough, which is concerning considering that physical inactivity is the fourth leading risk factor for non-communicable diseases (e.g., cancer, diabetes, cardiovascular disease) (WHO, 2016). In 2008, non-communicable diseases accounted for approximately 5.3 million deaths around the world (Lee et al., 2012). It is therefore important to promote physical activity engagement, especially among groups that may be vulnerable to inactivity, such as transgender people (Jones, Haycraft, Brewin, Bouman \& Arcelus, 2017).

'Transgender' is an umbrella term used to describe people who experience incongruence between the gender they were assigned at birth and their gender identity. Transgender males are people who were assigned female at birth but who later identify as male. Transgender females are people who were assigned male at birth but later identify as female. Cisgender people (non-transgender) do not experience incongruence between their assigned gender and gender identity. Some transgender people may choose to change their social gender role, but not necessarily undergo gender confirming medical treatments (e.g., cross-sex hormones, gender confirming surgery) (Beek et al., 2015; Coleman et al., 2012; Wylie et al., 2014), but many do. Cross-sex hormone treatment (oestrogen or testosterone) induce the development of secondary sex characteristics, which align with experienced gender (e.g., breast growth for 
transgender females, increase in muscle mass and lowering of voice for transgender males). In addition, some transgender people will choose to undergo irreversible gender confirming surgeries to create a male or female chest and genitals.

People who attend transgender health services have reported (at the time of first contact with the service) high levels of mental health problems (specifically anxiety, depression and selfharm) in comparison to cisgender people (Arcelus, Claes, Witcomb, Marshall \& Bouman, 2016; Bouman et al., 2016; 2017; Davey, Arcelus, Meyer \& Bouman, 2016; Dhejne, Van Vlerken, Heylens \& Arcelus, 2016; Millet et al., 2017). Although mental health difficulties do not prevent a transgender person accessing transgender healthcare, it may be necessary in some circumstances to manage these difficulties prior to gender confirming medical treatment (Coleman et al., 2012; Wylie et al., 2014).

Within cisgender populations, physical activity and sport have been found to alleviate symptoms of depression and anxiety (e.g., De Moor et al., 2006; Maltby \& Day, 2001). In view of this, the National Health Service (NHS) in the United Kingdom (UK) recommends engaging in physical activity three times a week (at least 45 minutes each day) to alleviate mild to moderate depression (National Institute for Health and Care Excellence, 2016). Social support has also been found to be a product of physical activity and sport participation within the cisgender population (e.g., Armstrong \& Oomen-Early, 2009). Based on these findings, engaging in frequent physical activity and/or sport may be particularly beneficial in relation to the mental well-being of transgender individuals. Furthermore, physical activity and sport participation can also contribute towards reaching the appropriate weight necessary to undergo some gender confirming surgeries. Kohl and Cook (2013) emphasise the importance of promoting physical activity to young people and providing them with ongoing opportunities to 
be active, as health-related behaviours (e.g., physical (in)activity) have been shown to track from childhood into adulthood.

Research that has explored levels of physical activity in transgender people has found that aerobic, strength and flexibility physical activity levels are low in comparison to cisgender people, when age and gender are controlled for (Jones et al., 2017). A recent systematic review concluded that transgender people on the whole have a negative experience when engaging in physical activity and competitive sport due to specific barriers relating to gender identity (e.g., changing facilities), transphobic behaviour (i.e., discrimination and violence relating to gender identity), lack of awareness about the needs of transgender people in physical activity and sport environments, and discriminatory policies for transgender people in competitive sport (Jones, Arcelus, Bouman \& Haycraft, 2016). However, this systematic review found that most studies were concerned with competitive sport, highlighting the dearth of research concerning sport and physical activity that is engaged in for leisure and fitness. Such research is important considering that most people who attend transgender health services will not be involved in competitive sport. Additionally, the studies reviewed did not consider the stage of transition of their participants (e.g., social transition, medical transition) and the implications this may have on physical activity levels.

A recent qualitative study has demonstrated how the stage of transition is significant when understanding physical activity and sport engagement in transgender people. EllingMachartzki (2015) found that, post-transition, transgender people felt less ashamed of their bodies and therefore more comfortable when engaging in physical activity and sport than they did pre-transition. However, the mean age of the participants in Elling-Machartzki's (2015) study was quite high (40.5 years, range 27-51) which may have affected the amount of physical 
activity participants engaged in as levels of physical activity have been found to decrease with age (e.g., British Heart Foundation, 2015). Therefore, when investigating physical activity among a specific population, age would be an important variable to consider. To date, no research has explored the experiences of young transgender adults (18-39 years) in relation to engaging in physical activity and sport.

With the intention of addressing the limitations of previous literature, the current study was interested in understanding what factors are associated with physical activity and sport engagement in young transgender adults who are medically transitioning. To adequately address the research aim, participants were purposefully recruited from a transgender health service in the UK once gender confirming medical treatment had been initiated. Given the lack of research with young transgender adults undergoing medical transition regarding their physical activity and sport participation, an inductive qualitative approach was seen as appropriate. One of the main advantages of this methodology is the rich and in-depth understanding of participant experience that it provides.

\section{Method}

Recruitment and Participants: Participants were recruited through a national transgender health service within the UK. This service is part of the NHS and offers assessment and treatment for transgender people who wish to transition. During a routine appointment at the service, young adult patients who had begun treatment were invited to take part in the research. The study was approved by an NHS ethics committee and also received University ethical approval from the first author's institution. 
In total, 14 participants were recruited into the study from the transgender health service; nine transgender males and five transgender females. The gender difference seen is solely a reflection of people who agreed to participate in the study. The participants were recruited over eight months during 2015/2016. The mean age of participants was 22.71 years (range 18-36). The sample size of this study is in line with recommendations for thematic analysis (e.g., Guest, Bunce, \& Johnson, 2006). Table 1 provides the demographic information of all participants in the study. Twelve out of the 14 participants currently engaged in physical activity or sport.

\section{INSERT TABLE 1 ABOUT HERE}

Interviews: Semi-structured interviews were conducted with all the participants in this study.

The majority of interviews were conducted face-to-face at the transgender health service $(n=11)$. For participants that could not travel to the NHS premises outside their scheduled appointment time, a telephone interview was conducted instead $(n=3)$. All interviews were audio recorded, transcribed verbatim and lasted an average of 24 minutes (range 15 to 37 minutes).

To guide the interviews, a semi-structured interview schedule was developed by consulting the relevant academic literature as well as clinicians working with transgender individuals. The interview schedule included questions pertaining to transgender people's experiences of physical activity and sport prior to, and across their transition.

Data analysis: Thematic analysis was employed to analyse the interviews and the guidelines

outlined by Braun and Clarke (2006) were followed. Thematic analysis provides a rich thematic description of the entire data set, which in turn highlights the most prominent and important 
themes (Braun \& Clarke, 2006). Five steps were followed. First, the first author read the interview transcripts whilst making notes on potential codes. Codes were then noted down the left margin, with a description of how the interviewee discussed the topic in the right hand margin. At this stage, an independent coder second coded approximately $20 \%(n=2)$ of the transcripts. Codes from both the first and second coder were then brought together to develop themes and subthemes, and relevant extracts to support these were identified. Themes and subthemes were then reviewed and refined by all the authors, creating a narrative and names for each theme/subtheme.

\section{Results}

Thematic analysis revealed two overarching themes: 1) barriers to engaging in physical activity and sport; 2) facilitators of physical activity and sport engagement. Within each of these overarching themes, two core themes were identified: i) internal (or personal) barriers/facilitators; ii) external (or environmental) barriers/facilitators. Within each theme, several subthemes were identified. See Table 2 for a summary of the themes and subthemes.

\section{INSERT TABLE 2 ABOUT HERE}

\section{1) Barriers to physical activity and sport}

This theme highlights the various barriers that participants experienced when engaging in (or attempting to engage in) physical activity and sport. Participants discussed their experiences in relation to both internal or personal barriers (e.g., body dissatisfaction) and external or environmental barriers (e.g., changing facilities). 
Physical activity and sport in young transgender adults

\subsection{Internal and personal barriers}

Three main subthemes grouped under 'internal and personal barriers' were described by the interviewees. Although each subtheme is described separately, it is noted that one almost certainly has an effect on the other and complete separation of these factors is not possible.

1.1.1. Gender incongruence: For the majority of participants $(n=10)$, the stage of transition and their gender incongruence were related to their physical inactivity. Some people who were previously physically active stopped such activity when socially transitioning:

"I stopped going [to the gym] when I socially transitioned" (Participant 09, transgender male)

"I was in a football team before everything [social transition] and I also did martial arts for five years "(Participant 08, transgender male)

Others who were hoping to enjoy the physical activity they used to enjoy, such as swimming (an activity where the body is highly visible), described no longer engaging in such activities as they had not yet seen the desired body changes expected from medical treatment (cross-sex hormones). The lack of body changes, and hence perceived lack of gender congruence, was mentioned by several participants as a reason why they had become physically inactive since they medically transitioned. The degree to which participants perceived they 'passed' as their gender identity (due to a lack of perceived gender congruence) was related to confidence levels:

"I haven't been on hormones for that long so the breast growth hasn't developed properly. It is sort of just lacking confidence in that sort of respect and how I come across which is stopping me" (Participant 12, transgender female) 
The gender incongruence that participants discussed appeared to be exacerbated in situations when the binary gender system was prominent. Changing rooms were mentioned numerous times by all interview participants and interlinked with several different themes and subthemes in this study, which magnifies the magnitude of this barrier. In the context of this subtheme, the participants perceived that their gender incongruence and an inability to 'pass' as their gender identity affected their use of changing rooms as they feared other users would judge them:

"I feel uncomfortable; I feel like people are looking at me going 'why are they going into the male changing rooms"," (Participant 06, transgender male)

1.1.2. Body dissatisfaction: All participants discussed how the severe body dissatisfaction they experienced (i.e., negative evaluation about one's appearance), defined by many participants as body dysphoria, was a barrier to engaging in physical activity and sport:

“When you feel so dysphoric with your body you can't manage to go and do sports or go and do the gym and things like that" (Participant 09, transgender male)

"I haven't been swimming but that is more of a confidence thing with body issues" (Participant 13, transgender female)

Engaging in physical activity appeared to heighten awareness of specific body parts that participants felt were not congruent with their gender identity when running or jumping, for example. For two participants, certain sportswear acted as a reminder of this incongruence due to the way it interacted with the body when being active:

"When you are running when the wind is blowing, your clothes sort of stick to you and that makes me feel quite dysphoric" (Participant 04, transgender male) 
The discomfort that participants felt in relation to their bodies also prevented them using changing facilities in public leisure centres, gyms and sports clubs. This was evidently perceived as a highly distressing environment by participants:

"I would have to be comfortable in my body [to use changing facilities] and I don't think that right now that is something I could do. I can't even think about it. It would be too much right now" (Participant 07, transgender female)

1.1.3. Anxiety about others' reactions: The majority $(n=8)$ of the participants discussed how they were concerned about others negatively evaluating their gender expression. The example quotation below illustrates how this anxiety was significant enough, for the majority of participants, to prevent them from engaging in physical activity and sport in public spaces:

“That fear of what other people think. Like you've always got that thing in your mind as if someone would just be like 'hold on, that's a girl'. That's why I don't like going to the gym" (Participant 08, transgender male)

Some $(n=5)$ participants also discussed avoiding changing facilities during their social and medical transition as they anticipated or experienced overt transphobia (i.e., discrimination, abuse, stigma of the basis of gender identity):

"I don't wanna be getting changed and y'know a cis guy comes in, he spots physical breasts and y'know beats me up" (Participant 03, transgender male)

"I actually have been into a changing room since I have changed to female and it didn't go very well. Someone complained to the head office at the reception and then they came in and told me that I wasn't allowed to be in there so that sort of put a downer on that and I haven't ever really done it since" (Participant 10, transgender female) 
However, the actual experience of verbalised negative evaluation or transphobia from others was rare. The majority of discussions held by participants $(n=13)$ indicated that this internal fear derived from beliefs of non-acceptance from others, perhaps due to previous negative experiences:

"[When I go to the gym] I feel like people are looking at me erm with knowledge that I am trans and I know that is impossible so I just ignore it just push it to the back of my mind" (Participant 06, transgender male)

"Nobody really ever said anything to me but it was just as you know there are a lot of big guys in the gym, and I mean like massive guys, so when somebody that they perceive to be a girl is in the gym like doing the same like in the same weight room as they are they kind of look at you a bit funny" (Participant 09, transgender male)

\section{External or environmental barriers}

Three subthemes were grouped under the core theme of 'external or environmental barriers'. Once again, the separation between themes and subthemes is artificial as one will likely be affected by another. Most of the external barriers mentioned were linked to the fear of being abused, judged negatively, treated differently or laughed at. These fears appeared to be more prevalent when the participants felt vulnerable, such as in changing rooms.

1.2.1. Changing and showering facilities: All participants in this study discussed how changing facilities in leisure centres or sports clubs were one of the biggest barriers to their participation in physical activity and sport. From the participants' discussions it was evident that the infrastructure of these facilities was the primary issue. When environments such as changing rooms are divided by the binary gender, people have to choose whether to enter one gendered 
facility or the other. All participants found changing facilities that were designed around the binary gendered system uncomfortable:

"General like awkwardness around things that are categorised into male and female and it is like where do you fit sometimes cos for all intents and purposes now that I have had my top surgery I fit perfectly into a male changing room but in any situation where I might have to take off my trousers for something then it is quite obvious I don't have a penis" (Participant 09, transgender male)

Participants were also concerned about others seeing their incongruent chest or genitals when changing or showering. This concern arose due to the openness and lack of privacy of such facilities, which was evidently uncomfortable:

"To have cubicle changing rooms and that would be ideal. It would just cut away all that rubbish as far as having to deal with open changing rooms and I think its intimidating anyway" (Participant 03, transgender male)

"I use the private one [changing facility] just because I don't feel very comfortable changing out of my swim clothes in the women's room because when they see me like that it is going to be a bit weird" (Participant 11, transgender female)

1.2.2. Sport-related clothing: Most participants $(n=11)$ discussed how sport-related clothing, stereotypically worn by males and females, was uncomfortable to wear when in public and engaging in physical activity or sport. The discussions held by participants suggested that this was due to the revealing nature of some clothing: 
Physical activity and sport in young transgender adults

“Well I would wear it [sports-related clothing] if I was on my own but I don't like my body and the shape. I wouldn't want to go and expose myself when exercising with other people” (Participant 07, transgender female)

"I am thinking along the lines of if I was wearing yoga pants and things like that and they were quite tight. So yes that would be an issue for me and that is probably why like whenever I go cycling I don't wear specific like cycling shorts I just wear like ordinary baggy shorts" (Participant 13, transgender female)

This was especially an issue in relation to swimwear which is highly revealing and can be an indication of one's gender (e.g., swimming shorts are worn by men and a costume by women):

"I have to think what sort of swimwear will I use because obviously there is going to be some bulging in the area and then that might trigger like nasty responses" (Participant 11, transgender female)

Several participants $(n=9)$ felt they could address this issue by wearing concealing sportswear (e.g., baggy t-shirts), however, to achieve this they had to compromise by deviating from clothing that is traditionally or stereotypically worn when engaging in that specific physical activity:

"I would wear like surf shorts that are a little like less revealing and a bit of a longer swimming top" (Participant 11, transgender female)

However, two participants clearly felt uncomfortable about having to adapt traditionally or stereotypically sportswear as they felt it drew unwanted attention towards them:

"Every time I have gone [to the gym] I have never felt comfortable because you see all the lads wearing sort of really revealing tops like vests and things like that and I 
Physical activity and sport in young transgender adults

am having to wear a full covered top and it gets you get all hot and sweaty you get people looking at you” (Participant 01, transgender male)

"The swimming pool is kind of a bit uncomfortable because I have to wear a $t$-shirt and it looks a bit weird" (Participant 04, transgender male)

Several participants (especially transgender males) also felt it was impossible prior to gender confirming surgery to both engage in physical activity or sport and conceal their breasts and genitals at the same time. All the transgender males within this study explained that to be physically comfortable during physical activity (e.g., unrestricted breathing), they could not wear a binder ${ }^{1}$ but to maintain a clear gender presentation and feel comfortable in public, they had to wear their binder:

"I can't really run around because I have my binder on all the time [and] I get very, very uncomfortable and I can't breathe. Pretty much that is the main reason why I don't do sport that involves seeing other people” (Participant 02, transgender male)

"I will probably run a lot more because it is quite awkward running because obviously you can't bind because it compresses your chest. But it is quite uncomfortable to have to not bind and you have to try and find somewhere to run where people are not going to see you" (Participant 04, transgender male)

What was significant here is how participants were more likely to engage in physical activity within the comfort of their homes as opposed to public spaces (e.g., gyms). Participants discussed how they did not feel it was necessary to maintain a clear gender expression or wear traditional sportswear when at home:

\footnotetext{
${ }^{1} \mathrm{~A}$ binder is an item of clothing worn under a t-shirt or shirt by transgender males pre-chest surgery. The binder minimises the chest area to give the appearance of a male chest.
} 
Physical activity and sport in young transgender adults

"If I am doing training in my room I can I usually just do it in my lounge wear so I don't have to worry about it. It's a lot more comfortable [not wearing a binder]" (Participant 02,

\section{transgender male)}

1.2.3. Team sports: Half of the participants $(n=7)$ spoke about how they were part of a sports team (e.g., football) or sports club (e.g., taekwondo) prior to socially transitioning (i.e., in their gender assigned at birth). However, at their current stage of medical transition, being involved in team sport was rare as participants felt that there was not a team that aligned with their gender identity or a gendered team they would comfortably fit into:

"I don't really fit into a bracket where I could play for a team anymore so I tend not to bother" (Participant 08, transgender male)

"It is quite hard to be part of a sport team because obviously like with the transition and everything I would have had to change sport teams and that's quite difficult" (Participant 04, transgender male)

Transgender men in this study also compared their size and strength levels to cisgender males and therefore felt it was difficult or dangerous to play against cisgender males. They understandably felt playing on a female team was out of the question:

"It is too aggressive for me to play on the male football team I'd end up getting like basically I have a fear of getting like broken and female football obviously I can't do that anymore" (Participant 08, transgender male)

The concern about their lack of strength appeared to be related to their low levels of testosterone pre-transition or during early medical transition:

"When I was on low levels of T [testosterone] and I was still kind of in a transitional state with it, it was difficult going to a man's rugby team. I started playing when I was 
quite weedy and small in comparison to these big old you know 28 year old blokes who are big and muscly" (Participant 14, transgender male)

\section{2) Facilitators of physical activity and sport}

This theme was divided into two core themes (internal and external/environmental facilitators), as per the previous theme, each of which had further subthemes (see Table 2).

\subsection{Internal facilitators}

In the general population, people are motivated to engage in physical activity and/or sport for health reasons, to change their appearance, and/or enjoyment (e.g., Salmon et al., 2003; Williams \& Cash, 2001). For the young transgender adults interviewed in this study, this was not different. However, specific motivating factors related to their transgender identity and transitional process, were mentioned which will be discussed in the following sections. As with the previous theme, subthemes are discussed separately, but are evidently interconnected.

\subsubsection{Body satisfaction as motivator to be physically active: Despite describing extreme} distress in relation to their bodies, most participants $(n=9)$ were motivated to use physical activity to increase body satisfaction and confidence:

"The dysphoria is a motivator to change it, it's not necessarily particularly comfortable but it is a motivator to change it into something that's more desirable" (Participant 03, transgender male)

"I suppose being more comfortable with my own body. I think that is probably the main motivation" (Participant 04, transgender male) 
The two participants that had undergone chest reconstructive surgery felt they engaged in more physical activity, or were more likely to engage in physical activity, where the body was more visible (e.g., swimming) as they felt more comfortable with it:

"We stayed in a hotel and had a bit of a swim and a dip and that is the first time I have been topless since the chest surgery" (Participant 14, transgender male)

When the other twelve participants were asked about their future physical activity and sport participation post-gender confirming surgery, they hypothesized that they would be more likely to engage in physical activity and sport in public and mainstream spaces due to an increase in body satisfaction:

"I'm not a member of the gym or anything but once, you know, once the top surgery's out of the way I will feel more confident using gym facilities. That's the only thing that's stopping me” (Participant 03, transgender male)

"I think that will be a real life changer [gender confirming surgery] because I will no longer be held back by situations like "oh what if that gym doesn't have cubicle showers" and "what if that changing room for swimming is all open", like it won't be an issue anymore because nobody would see the difference so I think that will definitely help" (Participant 09, transgender male)

\subsubsection{The accentuation of body changes as a motivator to be physically active: It was evident} that most of the female and male participants interviewed $(n=11)$ were striving to meet body ideals emphasized in Westernised culture (i.e., women are curvaceous but thin and men are a $\mathrm{V}$-shape and muscular). All but one of the transgender males in this study engaged in weight training (see Table 1). Building muscle for a young transgender man will likely improve their 
self-esteem and self-perception as their appearance becomes more congruous with what they perceive a stereotypical male physique to be:

"At the moment I am seeing a big progress. I am happy with like my arms they are starting to get bigger and I am starting to look more masculine, my shoulders are broader" (Participant 08, transgender male)

Several transgender males $(n=8)$ discussed how it was easier to achieve their masculine body ideal once cross-sex hormones had commenced. It was evident that they were motivated to increase their gender congruence (which affects their ability to 'pass' as their gender identity) by combining physical activity and the masculinising effects of testosterone:

"Like muscle like on the shoulders and arms and stuff erm it helps you pass better if you have got more muscles" (Participant 04, transgender male)

"I think that when you have got more muscle and you feel more defined and more toned you feel better and it is more socially acceptable as well so people tend to accept you more how you want them to" (Participant 09, transgender male)

One transgender female in this study spoke about the positive effects that the combination of cross-sex hormone treatment and physical activity had on the body:

"I am now happier with how my workout mixes in with my medication. I have noticed changes happening to certain parts of my body which makes me more comfortable with it" (Participant 12, transgender female)

There were noticeable gender differences in the appearance that transgender males and transgender female were aiming to accentuate. Whilst transgender males were striving for muscularity, one transgender female spoke about how she was attempting to achieve "a toning 
and slimming" effect which she felt was more achievable once cross-sex hormones had been initiated.

2.1.3. Gender confirming surgery as a motivator: There were a few participants $(n=4)$ in this study that discussed surgery as a motivator for engaging in physical activity. Participants recognised the importance of being in good physical health, and achieving a specific weight prior to gender confirming surgeries:

"I am motivated to go running just to keep healthy for future things like surgery" (Participant 10, transgender female)

"Yeah I guess that's another one as well being as fit and as healthy as I can for surgery as well" (Participant 03, transgender male)

Transgender males, pre-chest surgery, were especially aware of the benefits weight training would have in relation to surgical outcomes:

"I did a push-up app on my phone to try and get my shoulders and my chest just a bit muscly for surgery. It is better for your results if you do get a bit built before [surgery]" (Participant 09, transgender male)

\subsection{External facilitators or environmental facilitators:}

Finally, participants discussed physical activity and sport environments that felt more welcoming and accessible to them, and hence facilitated engagement in physical activity or sport.

2.2.1. Trans only environments: Several participants $(n=6)$ discussed the facilitating effect 'safe spaces' had on physical activity engagement. These 'safe spaces' were usually characterised by only including other transgender people and therefore participants perceived they would 
feel more comfortable, especially during their medical transition. Much of the discussion held by participants was hypothetical as these 'safe spaces' were not freely available. Several participants spoke about this in relation to 'trans specific' swimming groups:

"I think that would be a great idea because I've got friends that are trans as well that like swimming but won't go, so I think it would be something nice to go to a swimming pool with other people that are just like us. No one judges you” (Participant 08, transgender male)

"Like if it is made for transgender people [swimming group] then there is nothing to worry about is there?" (Participant 10, transgender female)

While the majority of participants felt that 'trans specific' spaces would encourage physical activity at their current stage of transition, some $(n=2)$ felt these spaces did not promote transgender inclusion in mainstream physical activity and sport:

"I know there are trans specific sort of swim sessions and I would not feel comfortable. I just rather integrate in and y'know not making it about a trans thing y'know. I'm just another guy going to the gym or going to the pool - do you know what I mean?" (Participant 03, transgender male)

\section{Discussion}

This study aimed to understand the factors which are associated with physical activity and sport engagement among young transgender people who are undergoing medical transition. Overall, young transgender adults are insufficiently active due to inadequate changing facilities, body dissatisfaction, fears surrounding 'passing' and not being accepted. At the same time, participants appeared to be motivated to engage in physical activity to increase their body 
satisfaction and gender congruence. Despite this motivation, participants felt there was a lack of 'safe' public environments (e.g., gyms) in which to engage in physical activity and sport.

One of the most significant findings of this study was the challenge that changing facilities imposed for the young transgender adults; a finding that supports previous research with older transgender adults (e.g., Hargie et al., 2015). The binary infrastructure of changing rooms and the lack of privacy was core to this challenge. Leisure centres and sport clubs should consider non-binary changing rooms, with private changing and showering cubicles. This would help transgender people access public physical activity and sport environments. However, the challenges that changing facilities imposed appeared to be much more deep-seated than this as body dissatisfaction, fears about passing, and the fear of transphobia interlinked with this barrier.

Despite all the participants being on cross-sex hormones which have been found to increase body satisfaction (Becker et al., 2016; Fisher et al., 2014), body dissatisfaction was still a significant barrier to physical activity and sport participation in the current study which has previously been found with older transgender people (mean age 40.5 years, range 27-51; Elling-Machartzki, 2015). The young transgender adults in the current study discussed how their bodies had not yet started to change or changed a significant amount in accordance with their gender identity and, hence, dissatisfaction was still problematic in relation to physical activity and sport. In contrast to previous research (Elling-Machartzki, 2015), the current study established an understanding as to why the body is a barrier. Participants explained how their awareness of incongruent body parts became heightened during physical activity, sometimes due to the sports clothing worn as it acted as a reminder of these body parts because of the way it interacted with the body. In addition, sports clothing for some sports can be clearly gendered (e.g., swimming costumes are worn by women and trunks by men) and revealing. Due to the 
Physical activity and sport in young transgender adults

high levels of dissatisfaction that participants in this study experienced with their bodies, they found such revealing clothing to be a barrier to their participation in physical activity and sport. In light of this, sports clothing brands should consider developing gender neutral and less revealing sportswear. This would be especially beneficial for sports such as swimming, gymnastics, athletics and cycling. Additionally, for the young transgender men in this study, concealing their chest and engaging in physical activity or sport in a safe and comfortable way was impossible. The development of effective (e.g., conceals chest) but more comfortable (e.g., less restrictive) and water-friendly chest binders would be a much welcomed product for this population.

The fear of being mis-gendered (i.e., not passing as the gender they identify with) was also core in explaining physical activity and sport disengagement in the current study. Concerns surrounding a lack of gender congruence were sometimes so significant that participants feared physical abuse from others. Previous research has found transgender people to avoid physical activity and sport due to transphobia (Hargie et al., 2015; Muchiock et al., 2014). However, in the current study it was found that for the majority of participant's negative evaluation from others and transphobia was anticipated as opposed to experienced. It may therefore be beneficial to develop interventions that challenge these negative thought processes, with the aim of encouraging physical activity and sport in public spaces (e.g., gyms, swimming pools, exercise classes). An intervention that is based on cognitive behavioural therapy and hence challenges negative thought process (e.g., you are not being judged, no one is going to hurt you) may be particularly beneficial in this context.

However, for the young transgender adults in this study, there was evidently the desire and motivation to engage in physical activity to increase gender congruence and body satisfaction. Engagement in physical activity in the current study was common, with 12 out the 14 
Physical activity and sport in young transgender adults

participants currently reporting to be active. This may be due to the fact that participants who were currently physically active felt motivated to take part in a study about physical activity and sport. This finding may also be explained by the participants' age as young people have been found to be more physically active then older people (e.g., British Heart Foundation, 2015). However, it is important to emphasise that physical activity was very rarely done in public spaces (e.g., gyms) as participants preferred to engage in physical activity within the comfort of their own homes. Participation in team based sport was also uncommon in those who took part in this study, which was also previously found by Hargie et al. (2015). The young transgender adults in our study commented on the difficulties of aligning with a gendered team (e.g., male or female) during their medical transition, a finding previously supported (Caudwell, 2012). However, in our study, transgender males were particularly concerned about the danger of playing with and against cisgender males as they felt their size and strength was not yet comparable. This is an important finding that needs to be addressed by sport organisations who need to make a conscious effort to increase sport participation and competition among the transgender population, especially given the psychosocial benefits team sport can have (e.g., Armstrong \& Oomen-Early, 2009). The development of mixed gendered teams that remove the pressure of being a certain size and strength would be beneficial. When the size of competitors is a concern, the Canadian Centre for Ethics in Sport (2016) suggests developing size categories, such as in wrestling. A few participants in this study pointed out that it may be unhelpful to create an abundance of 'trans only' sports club as this may further promote the exclusion of transgender people in mainstream sport. Instead, it may be more useful to increase awareness and acceptance of gender diversity within the public domain. This could be achieved through public campaigns that increase awareness of transgender people.

The findings from the current study suggest that socially and medically transitioning is core to physical activity and sport disengagement and that, once medical transition is complete, the 
barriers (and facilitators) are likely to change. Comments made by participants in this study suggest that physical activity and sport engagement will increase post-transition. Future research now needs to explore whether there are any differences in physical activity levels between transgender people post-transition and cisgender people, and if a difference is found, why.

This study is the first to explore the experiences of physical activity and sport in a young sample of treatment seeking transgender adults. Being specific in relation to the age and stage of transition of our participants will allow for specific interventions and initiatives (that promote physical activity) to be developed. However, there are some limitations to be taken into consideration. Three of the interviews were conducted via telephone and whilst the interviewer felt this method was as effective as the face-to-face interviews, telephone interviews have been criticised as important social cues cannot be responded to which can affect the rapport between interviewer and interviewee (e.g., Cook, 2012; Novick, 2008). This may have consequently affected the depth of data that was collected from these interviews. Another limitation of the study was the fact that the number of male $(n=9)$ and female $(n=5)$ participants was not equal and, while not expected, gender differences were found especially in relation to males (e.g., the issue with binders, building muscle). Future research may therefore want to consider recruiting a larger transgender female population (assigned male at birth) to further explore these gender differences.

\section{Conclusion}

There are a range of positive and negative factors that affect physical activity and sport engagement among young transgender adults who are medically transitioning. Internal (e.g., body dissatisfaction) and external (e.g., sport-related clothing) barriers prevent this population from engaging in physical activity and sport. Despite this, young transgender adults are 
motivated by body dissatisfaction and perceived gender incongruence to be physically active. However, due to the uncomfortable and unwelcoming environment that is sometimes experienced or anticipated in public physical activity and sport spaces (e.g., leisure centres), young transgender adults find it difficult to be physically active. Awareness of transgender people needs to be increased through public campaigns, and leisure centres and sports clubs need to consider ways in which they can make their spaces more accessible and welcoming for people with a variety of different gender identities (e.g., gender neutral changing facilities and showers). 


\section{References}

Arcelus, J., Claes, L., Witcomb, G. L., Marshall, E., \& Bouman, W. P. (2016). Risk factors for non-suicidal self-injury among trans youth. Journal of Sexual Medicine, 13, 402-412. doi: 10.1016/j.jsxm.2016.01.003

Armstrong, S., \& Oomen-Early, J. (2009). Social connectedness, self-esteem, and depression symptomatology among collegiate athletes versus non-athletes. Journal of American College Health, 57(5), 521-526. doi:10.3200/JACH.57.5.521-526

Ata, R. N., Ludden, A. B., \& Lally, M. M. (2007). The effects of gender and family, friend, and media influences on eating behaviors and body image during adolescence. Journal of Youth and Adolescence, 36, 1024-1037. doi: 10.1007/s10964-006-9159-x

Baker, L., \& Gringart, E. (2009). Body image and self-esteem in older adulthood. Ageing and Society, 29(06), 977-995. doi: 10.1017/S0144686X09008721

Beek, T.F., Kreukels, B.P.C., Cohen-Kettenis, P.T., Steensma, T.D. (2015). Partial gender request and underlying motives of applicants for gender affirming interventions. Journal of Sexual Medicine, 12(11), 2201-2205. doi 10.1111/jsm.13033

Becker, I., Nieder, T. O., Cerwenka, S., Briken, P., Kreukels, B. P., Cohen-Kettenis, P. T., ... \& Richter-Appelt, H. (2016). Body image in young gender dysphoric adults: A European multi-center study. Archives of Sexual Behavior, 45(3), 559-574. doi: 10.1007/s10508-015$0527-\mathrm{z}$

Bouman, W. P., Davey, A., Meyer, C., Witcomb, G. L. \& Arcelus, J. (2016). Predictors of psychological well-being among trans individuals. Sexual and Relationship Therapy, 31(3), 357-373. 
Bouman, W.P., Claes, L., Brewin, N., Crawford, J.R., Millet, N., Fernandez-Aranda, F., \& Arcelus, J. (2017). Transgender and anxiety: A comparative study between transgender people and the general population. International Journal of Transgenderism. Advance online publication. doi: 10.1080/15532739.2016.1258352

Braun, V. \& Clarke, V. (2006). Using thematic analysis in psychology. Qualitative Research in Psychology, 3(2), 77-101.

British Heart Foundation (2015). Physical Activity Statistics. Retrieved from: https://www.bhf.org.uk/ /media/files/publications/research/bhf_physical-activity$\underline{\text { statistics-2015feb.pdf }}$

Canadian Centre for Ethics in Sport. (2016). Creating Inclusive Environments for Trans Participants in Canadian Sport. Retrieved from: http://cces.ca/sites/default/files/content/docs/pdf/cces-transinclusionpolicyguidance-e.pdf Published 2016.

Caudwell, J. (2012). [Transgender] young men: gendered subjectivities and the physically active body. Sport, Education and Society, 19(4), 1-17. doi: $10.1080 / 13573322.2012 .672320$

Cook C. (2012). Email interviewing: generating data with a vulnerable population. Journal of Advanced Nursing, 68(6), 1330-1339. doi: 10.1111/j.1365-2648.2011.05843.x

Coleman, E., Bockting, W., Botzer, M., Cohen-Kettenis, P., DeCuypere, G.,...Zucker, K. (2012). Standards of Care for the Health of Transsexual, Transgender, and GenderNonconforming People, Version 7. International Journal of Transgenderism, 13(4), 165-232. doi: 10.1080/15532739.2011.700873 
Davey, A., Arcelus, J., Meyer, C., \& Bouman, W.P. (2016). Self-injury among trans individuals in transition and matched controls: Prevalence and associated factors. Health \& Social Care in the Community, 24(4), 485-494. doi: 10.1111/hsc.12239

Dhejne, C., Van Vlerken, R., Heylens, G., \& Arcelus, J. (2016). Mental health and gender dysphoria: A review of the literature. International Review of Psychiatry, 28(1), 44-57. doi: $10.3109 / 09540261.2015 .1115753$

De Moor, M. H. M., Beem, A. L., Stubbe, J. H., Boomsma, D. I., \& De Geus, E. J. C. (2006). Regular exercise, anxiety, depression and personality: a population-based study. Preventive Medicine, 42(4), 273-279. doi: 10.1016/j.ypmed.2005.12.002

Elling-Machartzki, A. (2015). Extraordinary body-self narratives: sport and physical activity in the lives of transgender people. Leisure Studies. Advance online publication. doi: $10.1080 / 02614367.2015 .1128474$

Fisher, A. D., Castellini, G., Bandini, E., Casale, H., Fanni, E., Benni, L., ... Rellini, A. H. (2014). Cross-Sex Hormonal Treatment and Body Uneasiness in Individuals with Gender Dysphoria. Journal of Sexual Medicine, 11, 709-719. doi: 10.1111/jsm.12413

Guest, G., Bunce, A., \& Johnson, L. (2006). How many interviews are enough? An experiment with data saturation and variability. Field Methods, 18(1), 59-82. doi: $10.1177 / 1525822 X 05279903$

Hargie, O. D., Mitchell, D. H., \& Somerville, I. J. (2015). "People have a knack of making you feel excluded if they catch on to your difference": Transgender experiences of exclusion in sport. International Review for the Sociology of Sport. Advance online publication. doi: $10.1177 / 1012690215583283$ 
Jankowski, G. S., Diedrichs, P. C., Williamson, H., Christopher, G., \& Harcourt, D. (2016). Looking age-appropriate while growing old gracefully: A qualitative study of ageing and body image among older adults. Journal of Health Psychology, 21(4), 550-561. doi: $10.1177 / 1359105314531468$

Jones, B. A., Arcelus, J., Bouman, W. P., \& Haycraft, E. (2016). Sport and transgender people: a systematic review of the literature relating to sport participation and competitive sport policies. Sports Medicine. Advance online publication. doi: 10.1007/s40279-016-0621-y

Jones, B. A., Haycraft, E., Brewin, N., Bouman, W. P. \& Arcelus, J. (2017). Physical activity in transgender people: A cross-sectional matched control study. Manuscript submitted for publication.

Kohl III, H. W., \& Cook, H. D. (2013). Educating the student body: Taking physical activity and physical education to school. National Academies Press.

Lee, I. M., Shiroma, E. J., Lobelo, F., Puska, P., Blair, S. N., Katzmarzyk, P. T. (2012). Effect of physical inactivity on major non-communicable diseases worldwide: an analysis of burden of disease and life expectancy. The lancet, 380(9838), 219-229. doi: 10.1016/S0140$6736(12) 61031-9$

Maltby, J., \& Day, L. (2001). The relationship between exercise motives and psychological well-being. Journal of Psychology, 135(6), 651-660. doi: 10.1080/00223980109603726

McGuire, J. K., Doty, J. L., Catalpa, J. M., \& Ola, C. (2016). Body image in transgender young people: Findings from a qualitative, community based study. Body Image, 18, 96-107. doi: 10.1016/j.bodyim.2016.06.004 
Millet, N., Longworth, J., \& Arcelus, J. (2017). Prevalence of anxiety symptoms and disorders in the Transgender population: A systematic review of the literature. International Journal of Transgenderism. Advance online publication. doi: 10.1080/15532739.2016.1258353

Muchicko, M. M., Lepp, A., \& Barkley, J. E. (2014). Peer victimization, social support and leisure-time physical activity in transgender and cisgender individuals. Leisure, 38 (3-4), 295-308. doi: 10.1080/14927713.2015.1048088

National Institute for Health and Care Excellence. (2016). Depression in adults: recognition and management. Treatments for mild to moderate depression. Retrieved from: https://www.nice.org.uk/guidance/cg90/ifp/chapter/tre§§atments-for-mild-to-moderatedepression

Novick, G. (2008). Is there bias against telephone interviews in qualitative research? Research in Nursing and Health, 31, 391-398. doi: 10.1002/nur.20259

Salmon, J., Owen, N., Crawford, D., Bauman, A., \& Sallis, J. F. (2003). Physical activity and sedentary behavior: a population-based study of barriers, enjoyment, and preference. Health psychology, 22(2), 178. doi: 10.1037/0278-6133.22.2.178

Williams, P. A., \& Cash, T. F. (2001). Effects of a circuit weight training program on the body images of college students. International Journal of Eating Disorders, 30(1), 75-82. doi: 10.1002/eat.1056

World Health Organisation. (2016). Physical activity: fact sheet. Retrieved from: http://www.who.int/mediacentre/factsheets/fs385/en/

Wylie, K., Barrett, J., Besser, M., Bouman, W. P., Bridgman, M., A.,... \& Rathbone, M. (2014). Good practice guidelines for the assessment and treatment of adults with Gender 
Physical activity and sport in young transgender adults

Dysphoria. Sexual and Relationship Therapy, 29(2), 154-214. doi:

$10.1080 / 14681994.2014 .883353$ 
Table 1: socio-demographics of participants included within the study

\begin{tabular}{|c|c|c|c|c|c|c|}
\hline Participant & $\begin{array}{l}\text { Age } \\
\text { (years) }\end{array}$ & Gender & $\begin{array}{l}\text { Stage of } \\
\text { transition }\end{array}$ & $\begin{array}{l}\text { Length of time on } \\
\text { CHT when } \\
\text { interviewed }\end{array}$ & $\begin{array}{l}\text { Currently engaging in } \\
\text { sport or physical } \\
\text { activity? }\end{array}$ & $\begin{array}{l}\text { Type of sport or physical } \\
\text { activity currently engaged in }\end{array}$ \\
\hline 01 & 18 & Transgender male & CHT & 1 month & Yes & $\begin{array}{l}\text { Football, muscle strengthening } \\
\text { exercises }\end{array}$ \\
\hline 02 & 18 & Transgender male & CHT & 4 months & Yes & $\begin{array}{l}\text { Tennis, muscle strengthening } \\
\text { exercises }\end{array}$ \\
\hline 03 & 33 & Transgender male & CHT & 4 months & Yes & $\begin{array}{l}\text { Muscle strengthening } \\
\text { exercises, cardio exercises }\end{array}$ \\
\hline 04 & 18 & Transgender male & $\mathrm{CHT}$ & 4 months & Yes & $\begin{array}{l}\text { Muscle strengthening } \\
\text { exercises, cardio exercises }\end{array}$ \\
\hline 05 & 18 & Transgender male & CHT & 11 months & Yes & $\begin{array}{l}\text { Muscle strengthening } \\
\text { exercises, cardio exercises }\end{array}$ \\
\hline 06 & 25 & Transgender male & CHT & 7 months & Yes & $\begin{array}{l}\text { Muscle strengthening } \\
\text { exercises, cardio exercises }\end{array}$ \\
\hline 07 & 18 & Transgender female & CHT & 6 months & No & NA \\
\hline 08 & 18 & Transgender male & CHT & 4 months & Yes & $\begin{array}{l}\text { Muscle strengthening } \\
\text { exercises, cardio exercises }\end{array}$ \\
\hline
\end{tabular}


Physical activity and sport in young transgender adults

\begin{tabular}{|c|c|c|c|c|c|c|}
\hline 09 & 23 & Transgender male & $\begin{array}{l}\text { CHT and double } \\
\text { mastectomy }\end{array}$ & 9 months & No & NA \\
\hline 10 & 18 & Transgender female & $\begin{array}{l}\text { CHT and } \\
\text { blockers }\end{array}$ & 2 years & Yes & Cardio \\
\hline 11 & 29 & Transgender female & CHT & 6 months & Yes & Squash, swimming \\
\hline 12 & 18 & Transgender female & CHT & 6 months & Yes & Muscle strengthening exercises \\
\hline 13 & 36 & Transgender female & $\begin{array}{l}\text { CHT and } \\
\text { blockers }\end{array}$ & 1 year & Yes & Cardio exercises \\
\hline 14 & 28 & Transgender male & $\begin{array}{l}\text { CHT and double } \\
\text { mastectomy }\end{array}$ & 3 years & Yes & $\begin{array}{l}\text { Rugby, muscle strengthening } \\
\text { exercises }\end{array}$ \\
\hline
\end{tabular}

Note: NA (not applicable), CHT (Cross-sex Hormone Treatment) 
Table 2: Core themes, themes and sub-themes identified from the thematic analysis

\begin{tabular}{|c|c|c|}
\hline Core themes & Themes & Sub-themes \\
\hline \multirow[t]{2}{*}{$\begin{array}{l}\text { 1. Barriers to physical } \\
\text { activity and sport }\end{array}$} & 1.1. Internal barriers & $\begin{array}{l}\text { 1.1.1. Gender incongruence } \\
\text { 1.1.2. Body dissatisfaction } \\
\text { 1.1.3. Anxiety about others } \\
\text { reactions }\end{array}$ \\
\hline & $\begin{array}{l}\text { 1.2. External or } \\
\text { environmental barriers }\end{array}$ & $\begin{array}{l}\text { 1.2.1. Changing facilitates } \\
\text { 1.2.2. Sport-related clothing } \\
\text { 1.2.3. Team sports }\end{array}$ \\
\hline \multirow[t]{2}{*}{$\begin{array}{l}\text { 2. Facilitators of physical } \\
\text { activity and sport }\end{array}$} & 2.1. Internal facilitators & $\begin{array}{l}\text { 2.1.1. Body satisfaction as a } \\
\text { motivator } \\
\text { 2.1.2. The accentuation of } \\
\text { body changes as a motivator } \\
\text { 2.1.3. Gender confirming } \\
\text { surgery as a motivator }\end{array}$ \\
\hline & $\begin{array}{l}\text { 2.2.External or environmental } \\
\text { facilitators }\end{array}$ & $\begin{array}{l}\text { 2.2.1. Trans only } \\
\text { environments }\end{array}$ \\
\hline
\end{tabular}

